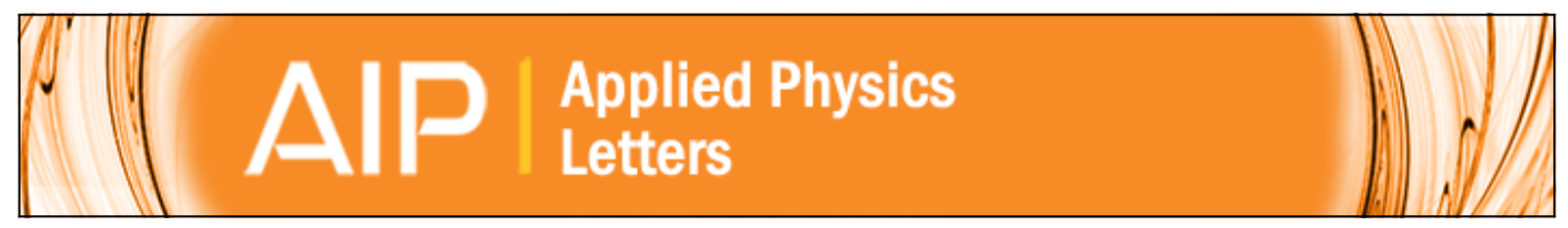

\title{
Compositional stability of hafnium aluminates thin films deposited on Si by atomic layer deposition
}

C. Driemeier, K. P. Bastos, L. Miotti, I. J. R. Baumvol, N. V. Nguyen, S. Sayan, and C. Krug

Citation: Applied Physics Letters 86, 221911 (2005); doi: 10.1063/1.1940130

View online: http://dx.doi.org/10.1063/1.1940130

View Table of Contents: http://scitation.aip.org/content/aip/journal/apl/86/22?ver=pdfcov

Published by the AIP Publishing

\section{Articles you may be interested in}

Probing compositional disorder in vanadium oxide thin films grown on atomic layer deposited hafnia on silicon by capacitance spectroscopy

J. Vac. Sci. Technol. A 30, 011501 (2012); 10.1116/1.3659020

Structural and electrical properties of Ti x Al $1-x \mathrm{O}$ y thin films grown by atomic layer deposition J. Vac. Sci. Technol. B 29, 01A302 (2011); 10.1116/1.3533763

Optical band gaps and composition dependence of hafnium-aluminate thin films grown by atomic layer chemical vapor deposition

J. Vac. Sci. Technol. A 23, 1706 (2005); 10.1116/1.2091096

Suppression of parasitic Si substrate oxidation in $\mathrm{HfO} 2$-ultrathin- Al $2 \mathrm{O} 3$ - Si structures prepared by atomic layer deposition

Appl. Phys. Lett. 86, 252110 (2005); 10.1063/1.1944206

Atomic-layer-deposited AI 2 O 3 thin films with thin SiO 2 layers grown by in situ O 3 oxidation

J. Appl. Phys. 96, 2323 (2004); 10.1063/1.1769090

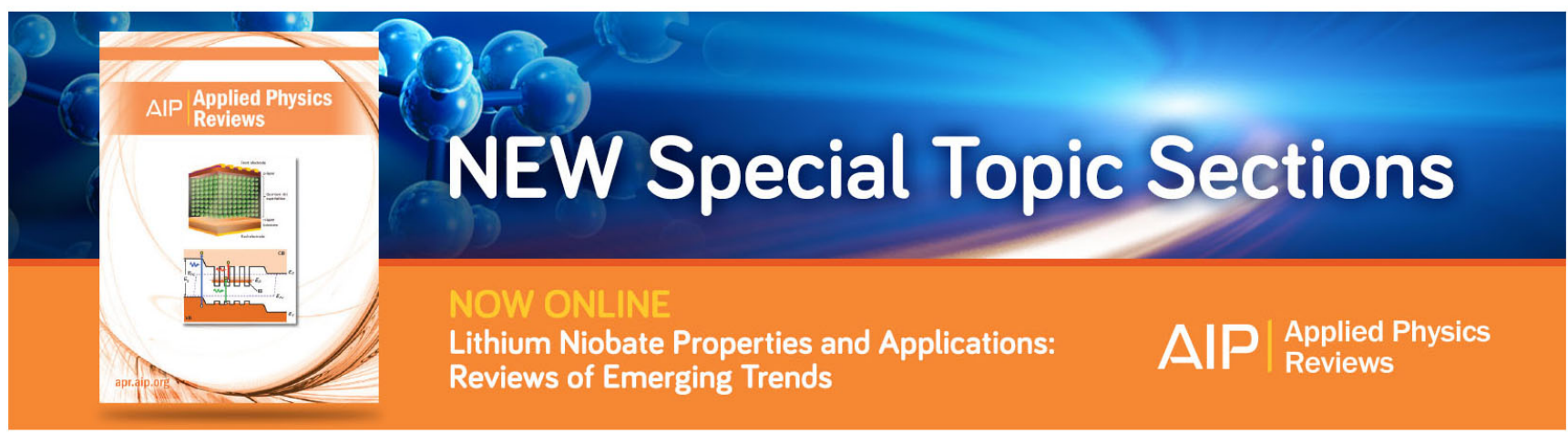




\title{
Compositional stability of hafnium aluminates thin films deposited on Si by atomic layer deposition
}

\author{
C. Driemeier, K. P. Bastos, and L. Miotti \\ Instituto de Física - UFRGS, CP 15051 Porto Alegre 91501-970, Brazil \\ I. J. R. Baumvol ${ }^{\text {a) }}$ \\ Universidade de Caxias do Sul, CCET and Universidade Federal do Rio Grande do Sul, 95070-560 Caxias \\ do Sul, Brazil
}

\author{
N. V. Nguyen \\ Semiconductor Electronics Division, National Institute of Standards and Technology, Gaithersburg, \\ Maryland 20899 \\ S. Sayan \\ Department of Chemistry, Rutgers University, Piscataway, New Jersey 08854 \\ C. Krug \\ Department of Physics, North Carolina State University, Raleigh, North Carolina 27695
}

(Received 31 January 2005; accepted 22 April 2005; published online 24 May 2005)

\begin{abstract}
We have used nuclear reaction analyses and Rutherford backscattering spectrometry to investigate quantitatively the compositional stability of hafnium aluminate thin films deposited on $\mathrm{Si}(001)$ by atomic layer deposition using $\mathrm{HfCl}_{4} / \mathrm{H}_{2} \mathrm{O}$ and $\mathrm{Al}\left(\mathrm{CH}_{3}\right)_{3} / \mathrm{H}_{2} \mathrm{O}$ precursors. It was found that increasing $\mathrm{Al} / \mathrm{Hf}$ deposition cycles ratio leads to increasing oxygen deficiency in the as-deposited films as well as to increasing metal losses (up to $\sim 15 \%$ ) from the films after rapid thermal annealing at $1000{ }^{\circ} \mathrm{C}$. Furthermore, isotopic substitution experiments, showed that incorporation of oxygen from the gas phase is eased in the cases where deposition conditions failed to supply enough oxygen to complete oxides stoichiometry. (C) 2005 American Institute of Physics. [DOI: 10.1063/1.1940130]
\end{abstract}

There is currently an intensive search for insulating materials holding high dielectric constant (high $k$ ) as alternatives to $\mathrm{SiO}_{2}$ or $\mathrm{SiN}_{x} \mathrm{O}_{y}$ gate dielectrics in metal-oxidesemiconductor field-effect transistor (MOSFET) devices. ${ }^{1,2}$ Any candidate to gate dielectric material should satisfy extreme requirements which include films and interfaces with low density of defects (such as suboxidized species and impurities), resistance to degradation during postdeposition thermal processing steps, and subnanometer thickness control of the high- $k$ film itself as well as of the interfacial low$k$ oxide (typically $\mathrm{SiO}_{2}$ ) that may be intentionally or unintentionally grown between the high- $k$ layer and the Si substrate.

Among the various alternative materials considered for gate dielectric application, probably $\mathrm{Al}_{2} \mathrm{O}_{3}$ and $\mathrm{HfO}_{2}$ are those which received more attention so far. ${ }^{3-5}$ A good tradeoff between the characteristics of these two materials ${ }^{1,6-11}$ can be achieved by forming $\left(\mathrm{HfO}_{2}\right)_{x}\left(\mathrm{Al}_{2} \mathrm{O}_{3}\right)_{1-x}$ mixed oxides, either homogeneous in composition or in nanolaminated structures. A convenient approach for depositing such films (oxides and mixed oxides) is the atomic layer deposition (ALD) technique, where self-saturating surface chemical reactions are employed. This approach ${ }^{5,6}$ has been successfully applied to control chemical reactions at the Si/high- $k$ and high- $k$ /gate electrode interfaces, as well as to obtain $\left(\mathrm{HfO}_{2}\right)_{x}\left(\mathrm{Al}_{2} \mathrm{O}_{3}\right)_{1-x}$ structures retaining sufficiently high dielectric constant and remaining amorphous up to high processing temperatures. Metastable defect configurations owing to the low-temperature film deposition process can be suppressed by postdeposition annealing. In particular, postdeposition annealing in oxygen containing atmospheres has

\footnotetext{
${ }^{\text {a) }}$ Author to whom correspondence should be addressed; electronic mail:
} israel@if.ufrgs.br been widely shown to improve electrical response of high- $k$ dielectrics.

We report here on the quantitative investigation of the composition and thermal stability of hafnium aluminates ultrathin films deposited on Si by ALD, as well as on oxygen incorporation and transport in these structures. After standard wet chemical cleaning of the $\mathrm{Si}(100)$ substrates (two solutions employed in sequence, namely $\mathrm{NH}_{4} \mathrm{OH}-\mathrm{H}_{2} \mathrm{O}_{2}-\mathrm{H}_{2} \mathrm{O}$ followed by $\mathrm{HCl}-\mathrm{H}_{2} \mathrm{O}_{2}-\mathrm{H}_{2} \mathrm{O}$. For details see Ref. 12), a thin layer of $\mathrm{SiO}_{2}$ grown by rapid thermal annealing (RTA) in $\mathrm{O}_{2}$ was produced. $\left(\mathrm{HfO}_{2}\right)_{x}\left(\mathrm{Al}_{2} \mathrm{O}_{3}\right)_{1-x} / \mathrm{SiO}_{2} / \mathrm{Si}$ structures were then grown layer by layer by $\mathrm{ALD}$ using $\mathrm{Al}\left(\mathrm{CH}_{3}\right)_{3} / \mathrm{H}_{2} \mathrm{O}$ (AO) and $\mathrm{HfCl}_{4} / \mathrm{H}_{2} \mathrm{O}(\mathrm{HO})$ as precursors at a substrate temperature of $300{ }^{\circ} \mathrm{C}$. We varied $\mathrm{AO} / \mathrm{HO}$ cycles ratio and the total number of cycles. The ALD sequences are given in the first column of Table I. Compositional stability and oxygen transport in these structures were investigated in selected samples (see Table I) by RTA in atmospheres of low pressure (between 0.1 and $10 \mathrm{mbar}$ ) $\mathrm{O}_{2}$ at two typical temperatures of MOSFET processing, namely postdeposition annealing at

TABLE I. Atomic layer deposition (ALD) sequences and number of cycles $(x)$ used in the selected samples for rapid thermal annealing (RTA). The last column shows the metal losses in each one of the selected samples after RTA at $1000{ }^{\circ} \mathrm{C}$ for $10 \mathrm{~s}$ in ${ }^{18} \mathrm{O}_{2}$. Typical errors in the determination of metal losses are approximately $10 \%$.

\begin{tabular}{ccc}
\hline \hline ALD sequences & Selected samples & $\begin{array}{c}\text { Metal loss }\left(2 \mathrm{~A}_{\mathrm{Hf}}+3 / 2 \mathrm{~A}_{\mathrm{Al}}\right) \\
\text { (at. \%) }\end{array}$ \\
\hline$x \mathrm{HO}$ & $x=92, \mathrm{HfO}_{2}$ & 5 \\
$x(1 \mathrm{AO}+5 \mathrm{HO})$ & $x=15, \mathrm{Hf}_{6} \mathrm{Al}_{2} \mathrm{O}_{15}$ & 9 \\
$x(1 \mathrm{AO}+1 \mathrm{HO})$ & $x=30, \mathrm{Hf}_{1} \mathrm{Al}_{2} \mathrm{O}_{5}$ & 14 \\
$x \mathrm{HO}+5 \mathrm{AO}+\mathrm{xHO}$ & $x=46, \mathrm{HfO}_{2} / \mathrm{Al}_{2} \mathrm{O}_{3} / \mathrm{HfO}_{2}$ & 8 \\
\hline
\end{tabular}



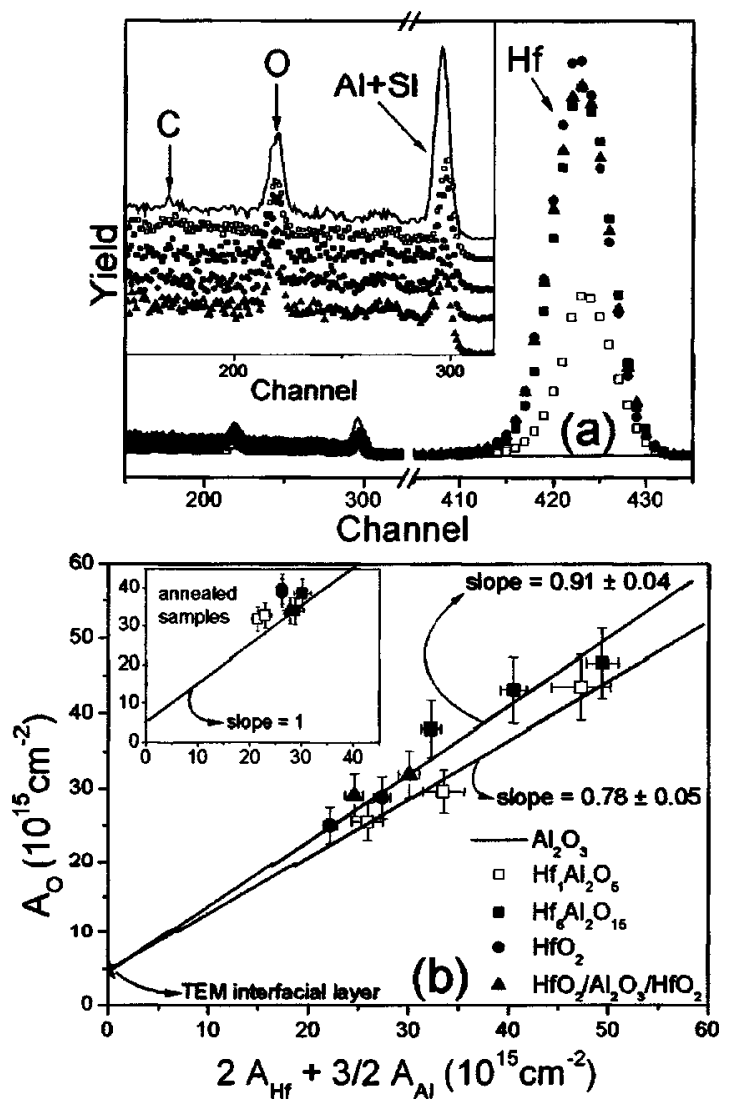

FIG. 1. (a) Rutherford backscattering spectra in channeled geometry (c-RBS). (b) Oxygen $\left(\mathrm{A}_{\mathrm{O}}\right)$ areal densities vs hafnium plus aluminum $\left(2 \mathrm{~A}_{\mathrm{Hf}}+3 / 2 \mathrm{~A}_{\mathrm{Al}}\right)$ areal densities for the different as deposits samples In the inset are plotted the areal densities of $\left({ }^{16} \mathrm{O}+{ }^{18} \mathrm{O}\right)$ vs $\left(2 \mathrm{~A}_{\mathrm{Hf}}+3 / 2 \mathrm{~A}_{\mathrm{Al}}\right)$ after rapid thermal annealing (RTA) at $1000{ }^{\circ} \mathrm{C}$ in ${ }^{18} \mathrm{O}_{2}$.

$600{ }^{\circ} \mathrm{C}$ and dopant activation annealing at $1000{ }^{\circ} \mathrm{C}$. The oxygen atmosphere in RTA was $\mathrm{O}_{2}$ enriched to $97 \%$ in the ${ }^{18} \mathrm{O}$ isotope $\left({ }^{18} \mathrm{O}_{2}\right)$,

Hf and ${ }^{16} \mathrm{O}$ contents in the films were simultaneously determined by Rutherford backscattering spectrometry in channeling geometry $(c$-RBS) and detection at grazing angle. ${ }^{13-15}$ Figure 1 (a) shows a set of such spectra, where the $\mathrm{Hf}$ and ${ }^{16} \mathrm{O}$ signals are indicated. The $\mathrm{Al}$ signal overlaps the substrate-Si signal in these spectra and therefore $\mathrm{Al}$ in the films had to be independently quantified. The ${ }^{27} \mathrm{Al}(p, \gamma){ }^{28} \mathrm{Si}$ nuclear reaction around the resonance in the cross section curve at $992 \mathrm{keV}$ was used for that purpose as performed in Ref. 5. These methods give precisions for $\mathrm{Hf}, \mathrm{Al}$ and $\mathrm{O}$ areal densities of about $3 \%, 10 \%$ and $10 \%$, respectively. The calculated, ideal approximate stoichiometries are given in the second column of Table I.

Figure $1(b)$ is a plot of the amounts of oxygen $\left(\mathrm{A}_{\mathrm{O}}\right)$ versus hafnium plus aluminum $\left(2 \mathrm{~A}_{\mathrm{Hf}}+3 / 2 \mathrm{~A}_{\mathrm{Al}}\right)$ from the different sequences of ALD cycles. Ideal, stoichiometric $\left(\mathrm{HfO}_{2}\right)_{x}\left(\mathrm{Al}_{2} \mathrm{O}_{3}\right)_{1-x}$ mixed oxide films should yield a straight line of unit slope crossing the origin. Linear fits to the data were made taking into account: (i) interfacial $\mathrm{O}$ amounts consistent with $1.1 \mathrm{~nm} \mathrm{SiO}$ interlayer determined by transmission electron microscopy (not shown). (ii) aluminum-rich $\mathrm{Hf}_{1} \mathrm{Al}_{2} \mathrm{O}_{5}$ films are evidently poorer in $\mathrm{O}$ when compared to Hf-richer samples and thus they were fitted separately. The fitting-derived slopes point to oxygen deficiency in asdeposited films. Previous results in $\mathrm{HfO}_{2}$ films described in the literature ${ }^{16,17}$ qualitatively support these findings. One
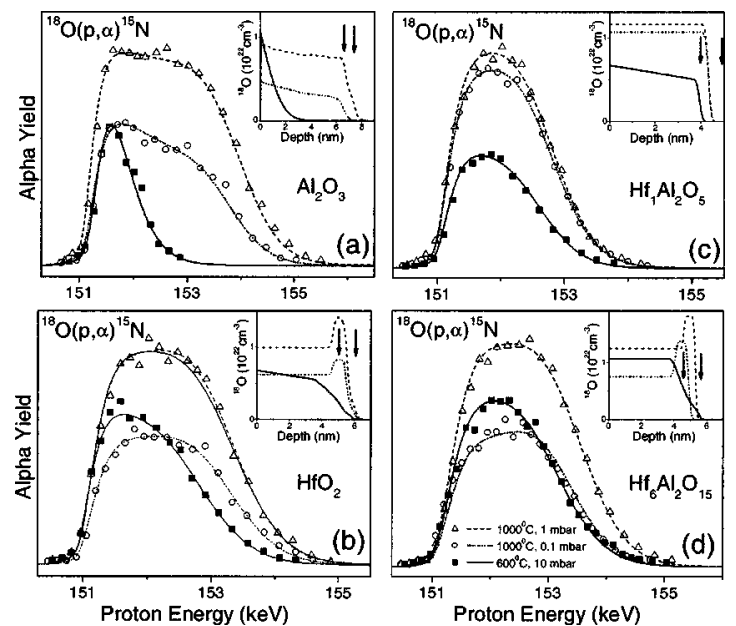

FIG. 2. Excitation curves of the ${ }^{18} \mathrm{O}(p, \alpha){ }^{15} \mathrm{~N}$ reaction around the narrow resonance at $151 \mathrm{keV}$. The corresponding ${ }^{18} \mathrm{O}$ profiles extracted from the simulation of the experimental curves are shown in the insets. The solid line in the excitation curve of Fig. 2(b) $\left(\mathrm{HfO}_{2}\right)$ represents a simulation performed assuming a constant ${ }^{18} \mathrm{O}$ concentration profile, whereas the dashed line represents a simulation performed assuming the profile shown in the inset.

observed that $\mathrm{HO}$ cycles performed on an aluminum oxide layer produced in an immediately precedent $\mathrm{AO}$ cycle lead to larger amounts of $\mathrm{Hf}$ incorporation per $\mathrm{HO}$ cycle as compared to $\mathrm{HO}$ cycles on $\mathrm{HfO}_{2}$, a fact that is also observed in Ref. 7. On the other hand, $\mathrm{O}$ deficiency increases with the $\mathrm{Al}$ content. Thus, one can associate $\mathrm{O}$ deficiency mainly with corresponding excessive $\mathrm{Hf}$ incorporation in $\mathrm{HO}$ cycles.

We performed rapid thermal annealing of the selected samples of Table $\mathrm{I}$ in the low pressures of ${ }^{18} \mathrm{O}_{2}$ range mentioned above, at $600{ }^{\circ} \mathrm{C}$ for $60 \mathrm{~s}$ and at $1000{ }^{\circ} \mathrm{C}$ for $10 \mathrm{~s} .{ }^{18} \mathrm{O}$ areal densities were determined using the ${ }^{18} \mathrm{O}(p, \alpha){ }^{15} \mathrm{~N}$ nuclear reaction in a plateau region of the cross section curve near $730 \mathrm{keV} .{ }^{18,19}$ Typical precision in ${ }^{18} \mathrm{O}$ amounts is $5 \%$. Elemental amounts for samples annealed at $1000{ }^{\circ} \mathrm{C}$ in 0.1 and $1 \mathrm{mbar}$ in ${ }^{18} \mathrm{O}_{2}$ are plotted in the inset of Fig. 1(b). The data points in the inset of Fig. 1(b) are at or above the stoichiometry, unitary slope line (solid line), indicating elimination of previously O-deficient sites as well as some eventual interface oxidation during oxygen annealing. Quantification of $\mathrm{Hf}$ and $\mathrm{Al}$, after RTA in ${ }^{18} \mathrm{O}_{2}$ or in vacuum at $1000{ }^{\circ} \mathrm{C}$ for $10 \mathrm{~s}$ showed (Table I) substantial metal losses. A tendency to higher metal losses in films containing more $\mathrm{Al}$ is manifested. Since we found that increasing Al content is related to increasing $\mathrm{O}$ deficiency, we propose that metal losses during RTA is also a mechanism of eliminating O-deficient sites remaining from film deposition.

Narrow resonance nuclear reaction profiling $(\mathrm{NRP})^{18,19}$ was also employed to determine ${ }^{18} \mathrm{O}$ profiles using the narrow $(\Gamma=100 \mathrm{eV})$ resonance at $151 \mathrm{keV}$ in the cross section curve of the ${ }^{18} \mathrm{O}(p, \alpha){ }^{15} \mathrm{~N}$ reaction, with an approximate depth resolution of $0.7 \mathrm{~nm}$ in near-surface regions. Excitation curves and the corresponding simulated concentration profiles (insets) are shown in Figs. 2(a)-2(d) for the homogeneous, mixed oxides of Table $\mathrm{I}$, as well as for a $7 \mathrm{~nm} \mathrm{Al} \mathrm{O}_{3}$ film grown by ALD on $\mathrm{SiO}_{2} / \mathrm{Si}(100)$ for comparison purposes. Arrows indicate the approximate position of the high $-k / \mathrm{SiO}_{2}$ and $\mathrm{SiO}_{2} / \mathrm{Si}$ interfaces as determined by calculated stopping power of protons in the materials. After RTA at $600{ }^{\circ} \mathrm{C},{ }^{18} \mathrm{O}$ holds a complementary error function (erfc) profile from the surface [Fig. 2(a)], far from reaching the 


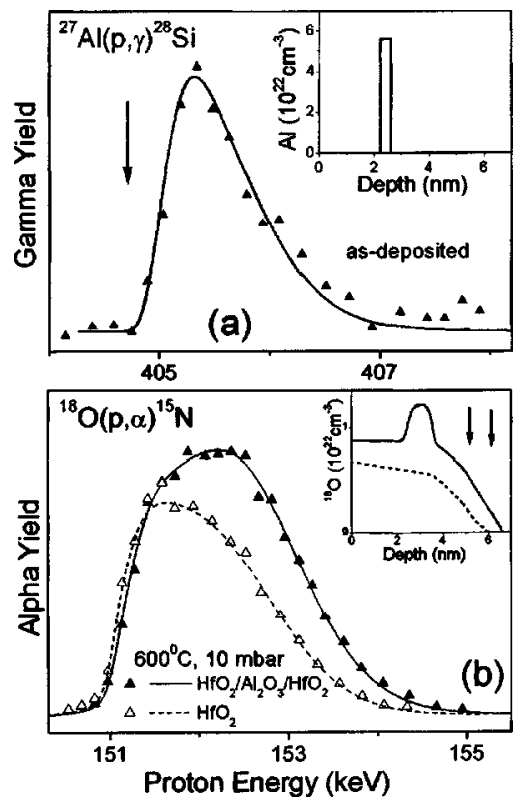

FIG. 3. (a) Excitation curve of the ${ }^{27} \mathrm{Al}(p, \alpha){ }^{28} \mathrm{Si}$ nuclear reaction around the narrow resonance at $404.9 \mathrm{keV}$. The extracted $\mathrm{Al}$ profile is shown in the inset. The arrow indicates the energy corresponding to $\mathrm{Al}$ at the sample surface. (b) Excitation curves of the ${ }^{18} \mathrm{O}(p, \alpha){ }^{15} \mathrm{~N}$ reaction around the narrow resonance at $151 \mathrm{keV}$ and ${ }^{18} \mathrm{O}$ profiles in the inset, after RTA in ${ }^{18} \mathrm{O}_{2}$.

$\mathrm{Al}_{2} \mathrm{O}_{3} / \mathrm{SiO}_{2}$ interface, which is typical of diffusion-limited ${ }^{18} \mathrm{O}$ incorporation. On the other hand, the rather flat ${ }^{18} \mathrm{O}$ profiles in the "bulk" of the Hf-containing films [Figs. 2(b)$2(\mathrm{~d})]$ and the propagation of the ${ }^{18} \mathrm{O}$ front down to the interface are clear indicatives that for Hf-containing films, even at such a low temperature as $600{ }^{\circ} \mathrm{C},{ }^{18} \mathrm{O}$ diffusion is much faster than its incorporation into the films.

${ }^{18} \mathrm{O}$ profiles from all films annealed (RTA) at $1000{ }^{\circ} \mathrm{C}$ are consistent with two regions with different characteristics. In near-surface regions, ${ }^{18} \mathrm{O}$ profiles are flat (almost flat for $\mathrm{Al}_{2} \mathrm{O}_{3}$ ), indicating fast diffusion. In near-interface regions, the incorporated ${ }^{18} \mathrm{O}$ results from the joint action of three mechanisms, namely ${ }^{18} \mathrm{O}-{ }^{16} \mathrm{O}$ exchange, oxidation of suboxidized species and substrate-Si oxidation, which lead to ${ }^{18} \mathrm{O}$ pileup shown in Figs. 1(b) and 1(d). Considering the flat ${ }^{18} \mathrm{O}$ profiles in the "bulk" of the films, one notices that the ${ }^{18} \mathrm{O}$ concentrations after RTA at $1000{ }^{\circ} \mathrm{C}$, in $1 \mathrm{mbar}$ of ${ }^{18} \mathrm{O}_{2}$, are quite similar $\left(\sim 10^{22} \mathrm{~cm}^{-3}\right)$ for all studied stoichiometries, indicating that ${ }^{18} \mathrm{O}$ incorporation rates into the films after RTA at $1000{ }^{\circ} \mathrm{C}$ are weakly dependent on stoichiometry. Furthermore, after RTA in 0.1 mbar of ${ }^{18} \mathrm{O}_{2}$ at $1000^{\circ} \mathrm{C}$, the ${ }^{18} \mathrm{O}$ concentration is significantly larger for the $\mathrm{Hf}_{1} \mathrm{Al}_{2} \mathrm{O}_{5}$ film, which was shown in Fig. 1(b) to be the most oxygen deficient one. The pressure independence of ${ }^{18} \mathrm{O}$ incorporation is due to the high thermal energy supplied at $1000^{\circ} \mathrm{C}$, which makes reactions fast enough such that the films will readily go towards a low energy, O-filled configuration even in very small oxygen partial pressures. is incorporated to occupy O-deficient sites.

In Fig. 3 we compare the ${ }^{18} \mathrm{O}$ profiles after RTA at $600{ }^{\circ} \mathrm{C}$ in ${ }^{18} \mathrm{O}_{2}$ for $\mathrm{HfO}_{2}$ and $\mathrm{HfO}_{2} / \mathrm{Al}_{2} \mathrm{O}_{3} / \mathrm{HfO}_{2}$ film samples on $\mathrm{Si}$. The only difference in the deposition of the two films is the intercalation of $5 \mathrm{AO}$ cycles in the middle of the $\mathrm{HfO}_{2}$ film deposition (see Table I) for the $\mathrm{HfO}_{2} / \mathrm{Al}_{2} \mathrm{O}_{3} / \mathrm{HfO}_{2}$ nanolaminate. The $\mathrm{Al}$ distribution in the nanolaminate was determined by $\mathrm{NRP}^{4}$ using the narrow
$(\Gamma=40 \mathrm{eV})$ resonance in the ${ }^{27} \mathrm{Al}(p, \gamma){ }^{28} \mathrm{Si}$ nuclear reaction cross section curve at $404.9 \mathrm{keV}$, whose excitation curve and the resulting ${ }^{27} \mathrm{Al}$ profile are shown in Fig. 3(a). The ${ }^{18} \mathrm{O}$ profiles in Fig. 3(b) clearly show a ${ }^{18} \mathrm{O}$ pileup near the $\mathrm{Al}-$ containing layer. Details on width and shape of this accumulated ${ }^{18} \mathrm{O}$ distribution cannot be precisely determined, but its existence is easily assured by the differences in shape of the two excitation curves. One can speculate that ${ }^{18} \mathrm{O}$ pileup would take place in the $\mathrm{HfO}_{2}$ atomic layers deposited on the $\mathrm{Al}_{2} \mathrm{O}_{3}$ layer since these $\mathrm{HfO}_{2}$ layers are highly $\mathrm{O}$ deficient and this deficiency would favor ${ }^{18} \mathrm{O}$ incorporation therein.

In summary, hafnium aluminate thin films of different thicknesses and stoichiometries were deposited on $\mathrm{Si}(001)$ by ALD using $\mathrm{HfCl}_{4} / \mathrm{H}_{2} \mathrm{O}$ and $\mathrm{Al}\left(\mathrm{CH}_{3}\right)_{3} / \mathrm{H}_{2} \mathrm{O}$ precursors. Quantitative analyses of the $\mathrm{Hf}, \mathrm{Al}$ and $\mathrm{O}$ amounts in the films indicate that as-deposited films are highly deficient in oxygen, this deficiency being higher for aluminates with higher $\mathrm{Al}$ content. Removal of $\mathrm{O}$ deficiencies takes place during RTA of the films in $\mathrm{O}_{2}$ by two parallel mechanisms, namely metal losses and incorporation of oxygen from the gas phase in previously O-deficient sites. Removal of deposition-related, metastable defects in postdeposition thermal processing steps here investigated is mandatory for successful integration of any candidate to gate dielectric for future MOSFET technology.

${ }^{1}$ High-k Dielectrics, edited by M. Houssa (Institute of Physics, London, 2004).

${ }^{2}$ G. D. Wilk, R. M. Wallace, and J. M. Anthony, J. Appl. Phys. 89, 5243 (2001).

${ }^{3}$ R. M. C. de Almeida and I. J. R. Baumvol, Surf. Sci. Rep. 49, 1 (2003). ${ }^{4}$ E. P. Gusev, M. Copel, E. Cartier, I. J. R. Baumvol, C. Krug, and M. A. Gribelyuk, Appl. Phys. Lett. 76, 176 (2000).

${ }^{5}$ M. M. Frank, Y. J. Chabal, M. L. Green, A. Delabie, B. Brijs, G. D. Wilk, M.-Y. Ho, E. B. O. da Rosa, I. J. R. Baumvol, and F. C. Stedile, Appl. Phys. Lett. 83, 740 (2003).

${ }^{6}$ D. C. Gilmer, R. Hegde, R. Cotton, R. Garcia, V. Dhandapani, D. Triyoso, D. Roan, A. Franke, R. Rai, L. Prabhu, C. Hobbs, J. M. Grant, L. La, S. Samavedam, B. Taylor, H. Tseng, and P. Tobin, Appl. Phys. Lett. 81, 1288 (2002).

${ }^{7}$ M.-Y. Ho, H. Gong, G. D. Wilk, B. W. Busch, M. L. Green, W. H. Lin, A. See, S. K. Lahiri, M. E. Loomans, P. I. Raisanen, and T. Gustafsson, Appl. Phys. Lett. 81, 4218 (2002).

${ }^{8}$ H. Y. Yu, N. Wu, M. F. Li, C. Zhu, B. J. Cho, D.-L. Kwong, C. H. Tung, J. S. Pan, J. W. Chai, W. D. Wang, D. Z. Chi, C. H. Ang, J. Z. Zheng, and S. Ramanathan, Appl. Phys. Lett. 81, 3618 (2002).

${ }^{9}$ M.-H. Cho, Y. S. Roh, C. N. Whang, K. Jeong, H. J. Choi, S. W. Nam, D.-H. Ko, J. H. Lee, N. I. Lee, and K. Fujihara, Appl. Phys. Lett. 81, 1071 (2002).

${ }^{10}$ R. J. Potter, P. A. Marshall, P. R. Chalker, S. Taylor, A. C. Jones, T. C. Q. Noakes, and P. Bailey, Appl. Phys. Lett. 84, 4119 (2004).

${ }^{11}$ A. Toriumi, T. Nabatame, and T. Horikawa, Mater. Res. Soc. Symp. Proc. 786, 135 (2004).

${ }^{12}$ W. Kern and D. A. Puotinen, RCA Rev. 31, 187 (1970).

${ }^{13}$ G. Amsel, J. P. Nadai, E. D'Artemare, D. David, E. Girard, and J. Moulin, Nucl. Instrum. Methods 92, 481 (1971).

${ }^{14}$ T. E. Jackman, J. R. MacDonald, L. C. Feldman, P. J. Silverman, and I. Stensgaard, Surf. Sci. 100, 35 (1980).

${ }^{15}$ L. C. Feldman, P. J. Silverman, J. S. Williams, T. E. Jackman, and I. Stensgaard, Phys. Rev. Lett. 41, 1396 (1978).

${ }^{16}$ J.-J. Ganem, I. Trimaille, I. C. Vickridge, D. Blin, and F. Martin, Nucl. Instrum. Methods Phys. Res. B 219-220, 856 (2004).

${ }^{17}$ K. Kuki, J. Aarik, T. Ustare, T. Sajavaara, J. Lu, J. Sundqvist, A. Aidia, L. Pung, A. Harsta. and M. Lesleka, J. Appl. Phys. 96, 5298 (2004).

${ }^{18}$ I. Vickridge and G. Amsel, Nucl. Instrum. Methods Phys. Res. B 45, 6 (1990).

${ }^{19}$ I. J. R. Baumvol, Surf. Sci. Rep. 36, 1 (1999). 